\title{
Dextran sulfate sodium-induced colitis-associated neoplasia: a promis- ing model for the development of chemopreventive interventions ${ }^{1}$
}

\author{
Margie Lee CLAPPER ${ }^{2,4}$, Harry Stanley COOPER ${ }^{3}$, Wen-Chi Lee CHANG ${ }^{2}$ \\ Divisions of ${ }^{2}$ Population Science and ${ }^{3}$ Medical Science, Fox Chase Cancer Center, Philadelphia, PA 19111, USA
}

\section{Key words}

colorectal colitis; chemoprevention; dextran sulfate sodium; mouse models

\footnotetext{
${ }^{1}$ This work was supported by USPHS grants CN05121, CA099122, and CA06927 from the National Cancer Institute, an ACS Institutional Research Grant, and by an appropriation from the Commonwealth of Pennsylvania. Its contents are solely the responsibility of the authors and do not necessarily represent the official views of the National Cancer Institute or the American Cancer Society.

${ }^{4}$ Correspondence to Prof Margie L CLAPPER. Phn 1-215-728-4301.

Fax 1-215-214-1622.

E-mail margie.clapper@fccc.edu
}

Received 2007-05-31

Accepted 2007-07-23

doi: $10.1111 / \mathrm{j} .1745-7254.2007 .00695 . \mathrm{x}$

\begin{abstract}
Individuals diagnosed with ulcerative colitis face a significantly increased risk of developing colorectal dysplasia and cancer during their lifetime. To date, little attention has been given to the development of a chemopreventive intervention for this high-risk population. The mouse model of dextran sulfate sodium (DSS) induced colitis represents an excellent preclinical system in which to both characterize the molecular events required for tumor formation in the presence of inflammation and assess the ability of select agents to inhibit this process. Cyclic administration of DSS in drinking water results in the establishment of chronic colitis and the development of colorectal dysplasias and cancers with pathological features that resemble those of human colitis-associated neoplasia. The incidence and multiplicity of lesions observed varies depending on the mouse strain used (ie, Swiss Webster, C57BL/6J, CBA, ICR) and the dose (0.7\%-5.0\%) and schedule (1-15 cycles with or without a subsequent recovery period) of DSS. The incidence of neoplasia can be increased and its progression to invasive cancer accelerated significantly by administering DSS in combination with a known colon carcinogen (azoxymethane (AOM), 2-amino-3-methylimidazo[4,5-f]quinoline (IQ), 2-amino-1methyl-6-phenylimidazo[4,5-b]pyridine (PhIP)) or iron. More recent induction of colitis-associated neoplasia in genetically defined mouse strains has provided new insight into the role of specific genes (ie, adenomatous polyposis coli $(A p c)$, $p 53$, inducible nitric oxide synthase (iNOS), Msh2) in the development of colitisassociated neoplasias. Emerging data from chemopreventive intervention studies document the efficacy of several agents in inhibiting DSS-induced neoplasia and provide great promise that colitis-associated colorectal neoplasia is a preventable disease.
\end{abstract}

\section{Introduction}

Inflammatory bowel disease (IBD), which includes ulcerative colitis and Crohn's disease, affects approximately one million individuals in the US each year ${ }^{[1]}$. Clinical studies have shown that patients with ulcerative colitis have a $2-8$ fold relative risk of developing colorectal cancer as compared to the general population. The risk of colorectal malignancies in colitis patients increases with the extent of colonic involvement, age of onset, severity and duration of disease $^{[2]}$. Recent data suggest a cumulative risk of malignancy below $1 \%$ for the first $8-10$ years, which increases in increments of $0.5 \%-1.0 \%$ annually, reaching $5 \%-10 \%$ after 20 years and $15 \%-20 \%$ after 30 years $^{[3]}$. It is estimated that
$25 \%-40 \%$ of ulcerative colitis patients who have not had a prophylactic colectomy will develop colorectal cancer after 40 years of having the diseas $\mathrm{e}^{[4]}$. It should be noted that data collected prospectively from a 30 -year surveillance program and reported recently suggest that the risk of colorectal cancer among patients undergoing surveillance may be lower than reported previously (cumulative incidence of $10.8 \%$ at

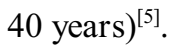

Although significant effort has been dedicated to the establishment of surveillance programs for individuals with ulcerative colitis, their effectiveness in preventing colitisassociated colorectal cancer remains controversial ${ }^{[5,6]}$. It is estimated that only $20 \%-50 \%$ of colorectal neoplasias are 
identified during routine colonoscopy ${ }^{[7]}$. The significant lag (at least 7 years) in the implementation of endoscopic screening in individuals with long-standing disease, indecisiveness regarding the optimal frequency of colonoscopies and the number of biopsies that should be obtained during the procedure, and the lack of strong adherence of physicians to existing guidelines make it extremely difficult to assess the value of such programs ${ }^{[6]}$. These limitations in clinical practice, when combined with the routine recommendation of colectomy for patients with colorectal dysplasia, dictate the critical need for early chemopreventive intervention in patients with ulcerative colitis.

Data from studies conducted to date suggest that the molecular targets for early chemopreventive intervention in colitis-associated colorectal carcinogenesis may differ from those of sporadic colorectal cancer. Although significant overlap exists between the genetic alterations associated with these two colorectal diseases, the timing of these events is distinct. Mutation of adenomatous polyposis coli (APC), the putative gatekeeper of sporadic colorectal carcinogenesis, is a late event in ulcerative colitis, occurring primarily in high-grade dysplasias and cancers ${ }^{[8,9]}$. In direct contrast, mutation or loss of heterozygosity ( $\mathrm{LOH})$ of $p 53$, a hallmark of late-stage sporadic colorectal cancer, is a frequent event in both inflamed, non-neoplastic mucosa and dysplasias $^{[10]}$. Mutational events during this early time period have been attributed to microsatellite instability induced by inflammation-associated oxidative stress ${ }^{[11,12]}$. It is interesting to note that $\mathrm{LOH}$ of $17 \mathrm{p}$ ( $p 53$ gene locus) is found more frequently in flat dysplasias as compared to polypoid dysplasias, while the percentage of each subtype exhibiting $\mathrm{LOH}$ of 5p (APC gene locus) is comparable ${ }^{[13]}$. Based on the association of $k$-ras mutations with the polypoid growth of sporadic colorectal adenomas ${ }^{[14]}$ and their presence in only $30 \%$ of colitis-associated cancers ${ }^{[15]}$, it has been suggested that flat dysplasias develop in the absence of $k$-ras mutations.

Reliable, reproducible and clinically relevant animal models of colitis are needed to identify the molecular events associated with disease progression and to develop efficacious strategies for tumor inhibition. It is essential that models chosen for study closely mimic the course of human ulcerative colitis, ultimately leading to the development of colorectal tumors that are pathologically similar to those of humans. The dextran sulfate sodium (DSS) model of induced colitis is an excellent preclinical model that exhibits many phenotypic features of relevance to human ulcerative colitis. The DSS model was originally described by Ohkusa ${ }^{[16]}$ as a hamster model and was adapted to mice subsequently by Okayasu et $a l^{[17]}$ and this group ${ }^{[18]}$. In general, acute colitis is induced in mice by administering the resin DSS in the drinking water at a concentration ranging from $1 \%-5 \%{ }^{[18-20]}$ for several days. Exposure to DSS for $1-4$ cycles (each cycle $=$ 3-7 d of DSS followed by untreated water; total $21 \mathrm{~d}$ ) mimics the active and inactive disease experienced by humans, leading to ulceration of the colonic mucosa and the establishment of chronic colitis (inflammation). The resulting pathological features of murine DSS-induced colitis-associated neoplasia have been characterized extensively by this group and others on different genetic backgrounds, in the presence of known colon carcinogens/promoters and in genetically modified mouse strains.

\section{DSS alone}

Based on differences in the sensitivity of mouse strains to DSS exposure, it is essential to optimize the DSS regimen for the production of both inflammation and colorectal tumors in each mouse strain of interest.

The protocol routinely employed by this group for outbred female Swiss Webster mice is 4 cycles of treatment, with each cycle consisting of $7 \mathrm{~d}$ of DSS followed by $14 \mathrm{~d}$ of untreated water (Table 1). The histological alterations are characteristic of those observed in patients with ulcerative colitis $^{[18,20]}$. First, after $7 \mathrm{~d}$ of DSS, there is loss of crypts and ulceration. Following one cycle (and subsequent cycles), the mucosa shows regenerative changes, distinctive glandular disarray, separation, shortening of crypts and crypt branching as seen in human chronic ulcerative colitis. In some mice, changes associated with activity are still present. A subset of mice exhibit the characteristic histopathologic features of ulcerative colitis many months after the discontinuation of DSS. Second, 4 cycles of DSS results in the development of colitis-associated dyplasias and adenocarcinomas in approximately $15 \%-20 \%$ of mice ${ }^{[20]}$. This percentage is comparable to the risk of ulcerative colitis patients developing dysplasia and/or cancer over time, providing a model system in which to investigate the molecular basis for the susceptibility of only certain individuals to tumor formation. Also, as in humans, longevity of disease is associated with a higher incidence of colitis-associated neoplasia. If Swiss Webster mice are allowed to live an additional $120 \mathrm{~d}$ after 4 cycles of DSS, the incidence of dysplasia and/or cancer increases from $15 \%-20 \%$ to $37.5 \%$, and the incidence of cancer increases from $9.3 \%$ to $25 \%$ compared to mice sacrificed after 4 cycles of DSS ${ }^{[20]}$. Third, as in humans, mice develop flat neoplastic lesions as well as polypoid neoplasias superimposed on chronic colitis (Figure 1). The potential relevance of the observation that invasive cancers arise more 
Table 1. Comparison of DSS-induced Colitis-Associated Colorectal Neoplasms in Swiss Webster and C57BL/6J Mice.

\begin{tabular}{|c|c|c|c|c|c|c|c|c|}
\hline \multirow[t]{2}{*}{ Strain } & \multirow[t]{2}{*}{ Treatment } & \multirow{2}{*}{$\begin{array}{c}\text { Cycles } \\
\text { (Days of } \\
\text { DSS/cycle) }\end{array}$} & \multirow{2}{*}{$\begin{array}{l}\text { Tumor } \\
\text { Incidence } \\
(\%)\end{array}$} & \multirow{2}{*}{$\begin{array}{c}\text { Tumor } \\
\text { Multiplicity }^{\mathrm{a}} \\
\text { (Mean } \pm \text { SEM) }\end{array}$} & \multicolumn{2}{|c|}{$\begin{array}{c}\text { Incidence of Neoplastic } \\
\text { Lesions }(\%)\end{array}$} & \multirow{2}{*}{$\begin{array}{c}\text { Invasive } \\
\text { Carcinoma } \\
(\%)\end{array}$} & \multirow[t]{2}{*}{ Reference } \\
\hline & & & & & Polypoid & Flat & & \\
\hline Swiss Webster & $4 \% \mathrm{DSS}$ & $4(7)$ & 18.6 & $1.2 \pm 0.1$ & 40 & 60 & 9.3 & 20 \\
\hline Swiss Webster & $4 \% \mathrm{DSS} / \mathrm{AOM}^{\mathrm{b}}$ & $3(7)$ & 100 & $13.6 \pm 2.7$ & 37.4 & 46.7 & 0 & 23 \\
\hline $\mathrm{C} 57 \mathrm{BL} / 6 \mathrm{~J}$ & $4 \% \mathrm{DSS}$ & $4(4)$ & 12.5 & $1.0 \pm 1.0$ & 100 & 0 & 0 & 22 \\
\hline $\mathrm{C} 57 \mathrm{BL} / 6 \mathrm{~J}$ & $4 \% \mathrm{DSS} / \mathrm{AOM}^{\mathrm{b}}$ & $3(4)$ & 100 & $14.8 \pm 2.2$ & 40 & 60 & 0 & $\begin{array}{l}\text { Chang, W-C, } \\
\text { personal } \\
\text { communication }\end{array}$ \\
\hline
\end{tabular}

${ }^{\mathrm{a}}$ Calculated for tumor-bearing mice only; ${ }^{\mathrm{b}}$ Single injection (ip) $-7.4 \mathrm{mg} / \mathrm{kg}$

frequently from flat lesions is of great concern, considering our current inability to accurately detect these lesions in humans using standard endoscopic surveillance protocols. Finally, the contribution of inflammation to the dysplasia/ cancer sequence is significant. DSS-treated Swiss Webster mice with dysplasias/cancers have significantly higher mean colonic inflammation scores than those without dysplasias or cancers ${ }^{[20]}$. Interestingly, inflammation scores are significantly higher in cancers $v s$ dysplasias.

Several observations in the Swiss Webster model of DSSinduced colitis suggest that the genetic profile of flat and polypoid lesions may differ. First, flat lesions exhibit significantly higher inflammation scores than polypoid lesions. Second, cancers arise more frequently from flat mucosa ${ }^{[20]}$.
Third, nuclear translocation of $\beta$-catenin is observed in the majority of DSS-induced polypoid lesions, while $\beta$-catenin remains localized to the cell membrane of flat dysplasias and cancers. Fourth, Nosho and colleagues ${ }^{[21]}$ demonstrated recently that hierarchical clustering of the gene expression profiles of human colon adenomas results in the independent segregation of flat and protruding lesions. While lesions from IBD patients were not evaluated in this study, a similar result is anticipated based on our observations.

A DSS regimen, similar to that described above, has been used to induce colitis in inbred female $\mathrm{C} 57 \mathrm{BL} / 6 \mathrm{~J}$ mice. A total of $12.5 \%$ ( 1 of 8 ) of wild-type female C $57 \mathrm{BL} / 6 \mathrm{~J}$ mice exposed to $4 \%$ DSS for 4 cycles ( $4 \mathrm{~d}$ of DSS plus $17 \mathrm{~d}$ of water) developed dysplasias. In contrast to DSS-treated Swiss Webster

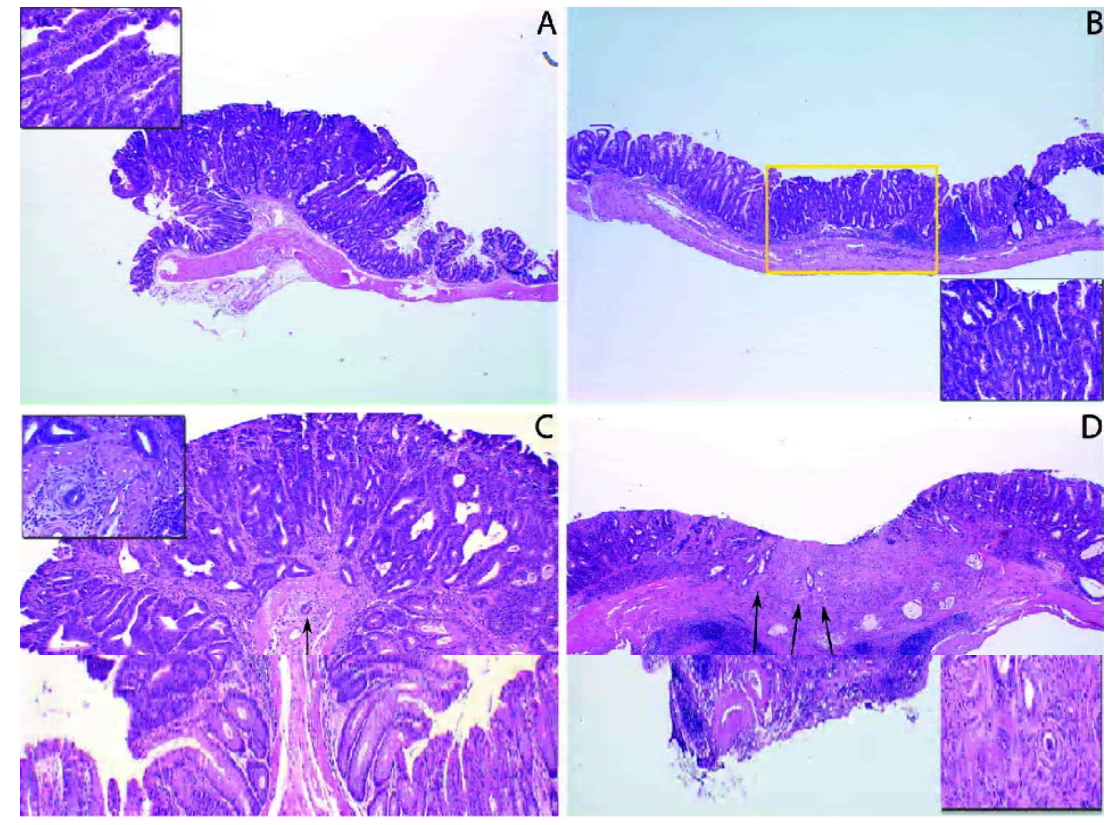

Figure 1. (A) Low-power view of a polypoid dysplasia. Note that the lesion projects above the surface of the colon, $\times 4$. Insert: highpower view of dysplasia, $\times 40$. (B) Low-power view of flat dysplasia (yellow box). The dysplasia is of the same height as the surrounding nonneoplastic mucosa, $\times 4$. Insert: highpower view of dysplasia, $\times 40$. (C) Low-power view of polypoid adenocarcinoma. The arrow points to a malignant gland that has invaded into the submucosa, $\times 10$. Insert: the malignant gland invading into the submucosa has elicited a desmoplastic reaction, $\times 40$. (D) Low-power view of a flat adenocarcinoma (arrows). The cancer is invading into the muscularis propria, $\times 4$. Insert: a high-power view of invasive malignant glands and the desmoplastic response they elicited, $\times 40$. 
mice, no cancers were observed ${ }^{[22]}$ (Table 1$)$.

\section{DSS in combination with a colon carcinogen/ promoter}

Although the pathological features of the Swiss Webster mice with DSS-induced colitis mimic those of humans with ulcerative colitis, intervention studies in this model are costly due to the need for large numbers of animals to achieve statistical significance and the length of time required for tumor formation (a minimum of $84 \mathrm{~d}$ ). Carcinogens, such as azoxymethane (AOM) and heterocyclic amines (HCAs), and other promoters (ie, iron) have been added to the DSS regimen to enhance tumor incidence, multiplicity, and/or lesion progression.

AOM Based on the experience of this group, use of DSS in combination with AOM, a classic chemical carcinogen that induces colorectal cancer in rodents, results in $100 \%$ incidence of colonic tumors ${ }^{[23]}$ as compared to $15 \%$ $20 \%$ when DSS is administered alone (Table 1). Although the length of study can be shortened from 4 cycles to 3 cycles (63 d) of DSS due to the accelerated development of colorectal lesions, no invasive carcinomas are observed. It should be noted that no dysplasias are observed in mice receiving only AOM, suggesting that the dose of carcinogen used $(7.4 \mathrm{mg} / \mathrm{kg})$ is insufficient to induce colorectal tumors in the absence of inflammation. Tanaka and colleagues ${ }^{[24,25]}$ also observed enhanced development of colitis-associated neoplasia when ICR mice were injected with AOM prior to DSS exposure. Use of a lower percentage of DSS (1\%-2\% for 4-7 d) in combination with AOM was sufficient to induce colitis-associated neoplasia as long as the animals were allowed to live an additional 16-18 weeks following DSS exposure.

The morphology and representation of flat and polypoid lesions generated by AOM/DSS treatment is consistent with that observed following treatment with DSS alone (Table 1). However, in the presence of AOM and DSS, nuclear translocation of $\beta$-catenin is observed in both flat and polypoid lesions induced by AOM and DSS due to mutation of $\beta$-catenin. This finding is consistent with the presence of $\beta$-catenin mutations in AOM-induced colon lesions in the $\mathrm{rat}^{[26]}$ and mouse $\mathrm{e}^{[27]}$ and the altered distribution of $\beta$-catenin in human colitis-associated colorectal cancer ${ }^{[28]}$. Because of the small number of studies carried out on human samples to date, the role of $\beta$-catenin mutations in human colitis-associated neoplasia remains unclear ${ }^{[29]}$.

Strain differences in susceptibility to AOM/DSS have been reported ${ }^{[25]}$. Treatment of 4 different strains of mice (balb/c, C3H/HeN, C57BL/6N and DBA/2N) with an identical regimen of AOM/DSS by Suzuki et al ${ }^{[25]}$ resulted in distinct differences in tumor incidence, multiplicity and inflammation among the strains. In our hands, C57BL/6J mice were unable to tolerate the AOM/DSS regimen used for Swiss Webster mice ( $7 \mathrm{~d}$ of DSS plus $14 \mathrm{~d}$ of untreated water, over 3 cycles). The optimal protocol that we have established for this strain includes 3 cycles of abbreviated exposure to DSS ( $4 \mathrm{~d}$ of DSS and $17 \mathrm{~d}$ of untreated water). The survival rate of animals receiving AOM (control) or AOM/DSS (100\% and 60\%, respectively) is comparable to that of Swiss Webster mice receiving identical treatment (100\% and 56\%, respectively). These data suggest that genetic background may play an important role in dictating the risk of colitis-associated neoplasia.

Comparison of AOM/DSS-induced colitis-associated neoplasia in Swiss Webster (outbred) and C57BL/6J (inbred) mice reveals many similar features. First, all (100\%) female Swiss Webster and C57BL/6J mice developed colitis following exposure to AOM and DSS and with a similar degree of inflammation. Second, the incidence of colorectal dysplasias in $\mathrm{C} 57 \mathrm{BL} / 6 \mathrm{~J}$ mice receiving $\mathrm{AOM}$ alone or $\mathrm{AOM} / \mathrm{DSS}$ is $0 \%$ and $100 \%$, respectively; identical to that of treated Swiss Webster mice. Third, as in Swiss Webster mice, invasive cancers are not observed in AOM/DSS-treated C57BL/6J mice. Fourth, the mean multiplicity of colonic dysplasias observed in C57BL/6J mice exposed to AOM and DSS (15.4 2.3 , mean $\pm \mathrm{SEM})$ is comparable to that observed in AOM/DSStreated Swiss Webster mice (16.0 \pm 2.2$)$. Finally, similar percentages of flat and polypoid dysplasias (Table 1) are observed in AOM/DSS-treated C57BL/6J and Swiss Webster mice. These data demonstrate that, although $\mathrm{C} 57 \mathrm{BL} / 6 \mathrm{~J}$ mice are more sensitive to AOM/DSS exposure than outbred Swiss Webster mice, administration of AOM/DSS to inbred C57BL/ $6 \mathrm{~J}$ mice induces colitis-associated colonic dysplasias that are identical to those of AOM/DSS-treated Swiss Webster mice with respect to tumor incidence, multiplicity and morphology.

HCAs A variety of heterocyclic amines (HCAs), important food-derived carcinogens generated during heating amino acids and proteins ${ }^{[30-32]}$, have been evaluated for their ability to promote the formation of DSS-induced colitisassociated neoplasia. Of the HCAs examined to date, 2-amino1-methyl-6-phenylimidazo[4,5- $b$ ]pyridine (PhIP) elevated the incidence and multiplicity of total lesions and adenocarcinomas to the greatest extent as compared to either 2-amino-3,8dimethylimidazo[4,5-f]quinoxaline (MeIQx) or 2-amino-3methylimidazo[4,5-f]quinoxaline (IQ $)^{[27,33]}$. Both polypoid and flat colorectal neoplasias were observed in mice exposed to 
HCAs and DSS ${ }^{[27]}$. $\beta$-catenin mutations (codons 32 or 34) were found in all PhIP/DSS-induced adenocarcinomas and accompanied by strong nuclear and cytoplasmic staining of $\beta$-catenin ${ }^{[27]}$. These lesions also exhibited overexpression of cyclooxygenase-2 (COX-2) and iNOS protein.

Iron Oral iron supplements are routinely prescribed to patients with chronic ulcerative colitis to ameliorate any iron deficiency associated with colitis-induced anemia. Because iron is poorly absorbed in the upper gastrointestinal tract, the majority of oral iron reaches the colonic lumen where it reacts with superoxides and hydrogen peroxide to form hydroxyl radicals and other reactive oxygen species ${ }^{[34]}$. Results from animal studies suggest that iron may exacerbate colitis and enhance the formation of colitis-associated neoplasia ${ }^{[34,35]}$. Both disease activity and severity of colitis increased in a dose-dependent manner when DSS-treated animals were fed diets supplemented with iron ${ }^{[35]}$. Long-term exposure to an iron-enriched diet (2-fold) in combination with cyclic administration of $0.7 \%$ DSS caused a significant increase in the incidence of colorectal adenocarcinomas as compared to that of controls maintained on a standard diet and administered DSS (94\% and 38\%, respectively) $)^{[35]}$.

\section{DSS in genetically defined mouse models}

Apc $^{+/ \text {Min }}$ mouse model Mutation of the $A P C$ gene, the putative gatekeeper of colorectal tumorigenesis, occurs in more than $80 \%$ of sporadic colorectal cancer. In contrast, only $4 \%-27 \%$ of human colitis-associated colorectal cancers harbor mutant $A P C^{[2]}$. In order to determine the contribution of mutant $A P C$ to colitis-associated neoplasia, colitis was induced in $\mathrm{Apc}^{+/ \mathrm{Min}}$ mice carrying a germline mutation in $A p c$, and tumor incidence and multiplicity were evaluated ${ }^{[19,22]}$. Our study was carried out in a unique strain of $\mathrm{Apc}^{+/ \mathrm{Min}}$ mice, which, unlike the conventional strain, develop multiple adenomas in the large intestine ${ }^{[36]}$. Female C57BL/6J Apc ${ }^{+/ \text {Min-FCCC }}$ mice were treated with 2 cycles of DSS. Cycle 1 consisted of $4 \mathrm{~d}$ of $4 \%$ DSS plus $17 \mathrm{~d}$ of untreated water, and Cycle 2 consisted of $3 \mathrm{~d}$ of DSS plus $18 \mathrm{~d}$ of untreated water. Wildtype female C57BL/6J mice were treated with 4 cycles of DSS, with each cycle consisting of $4 \mathrm{~d}$ of $4 \%$ DSS plus 17 $\mathrm{d}$ of untreated water. DSS-treated animals exhibited a 2-fold increase in tumor incidence $(50 \%$ vs $100 \%)$ and a dramatic increase in tumor multiplicity (mean $1.9 \pm 0.7$ and $29.3 \pm 4.1$ for untreated and DSS-treated Apc ${ }^{+/ \text {Min-FCCC }}$ mice, respectively) (Table 1). No invasive colorectal cancers were observed in untreated $\mathrm{Apc}^{+/ \mathrm{Min}-\mathrm{FCCC}}$ mice, while $40 \%$ of DSS-treated mice had colorectal cancer. Tumor incidence in wild-type mice exposed to DSS was $12.5 \%$, and the mean number of tumors per tumor-bearing mouse was 1.0. Interestingly, all of the dysplasias in DSS-treated wild-type mice were polypoid; no flat lesions were found. The majority of the neoplastic lesions observed in both untreated and DSS-treated $\mathrm{Apc}^{+/ \text {Min-FCCC }}$ mice were also polypoid $(86.7 \%$ and $52.7 \%$, respectively). Dysplastic colorectal lesions from both untreated and DSS-treated Apc ${ }^{\mathrm{Min}}$ mice showed LOH of $A p c$ (100\% and $90.6 \%$, respectively). These findings indicate that both mutation of $A p c$ and inflammation accelerate the formation of colitis-associated dysplasias and their progression to invasive cancers. Even when colorectal carcinogenesis is driven by inflammation, $\mathrm{LOH}$ of $A p c$ remains a critical event in the formation of colorectal dysplasias.

The role of DSS-induced colitis as a promoter of neoplasia in $\mathrm{Apc}^{\mathrm{Min}}$ mice has also been studied by Tanaka et al ${ }^{[19]}$. In their experiment, mice were exposed to $2 \%$ DSS in the drinking water for $7 \mathrm{~d}$, followed by 4 weeks of untreated water (total of $35 \mathrm{~d}$ ). One hundred percent of the mice developed gross lesions with a multiplicity of $8.3 \pm 5$ (3.3 \pm 3 adenomas and $5.0 \pm 2$ adenocarcinomas). In addition, all mice developed microscopic dysplastic lesions (13.3 \pm 3.4 per mouse). One explanation for the higher incidence of adenocarcinomas in this study as compared to that of Cooper et $a l^{[22]}$ is the difference in the definition of adenocarcinoma. In the latter study, lesions were considered adenocarcinomas only when they had invaded through the muscularis mucosae and into the submucosa. In the study carried out by Tanaka et $a l^{[19]}, 100 \%$ of adenocarcinomas showed LOH of $A p c$. There was strong nuclear expression of p53 and $\beta$-catenin; however, no $\beta$-catenin mutations were detected. COX-2 and iNOS were strongly expressed in the cytoplasm of adenomas, adenocarcinomas, mononuclear cells and endothelial cells.

p53-deficient mouse model Results from many studies have suggested that loss of $p 53$ function is an early and critical event in colitis-associated colorectal cancer ${ }^{[10,37]}$; one that is perhaps comparable to the gatekeeper function of $A P C$ in sporadic colorectal carcinogenesis. In order to further investigate the function of $p 53$ in colitis-associated colorectal neoplasia, colitis was induced in $\mathrm{p} 53^{-/-}, \mathrm{p} 53^{+/}$, and

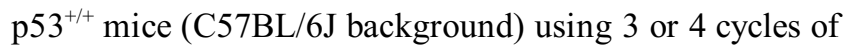
DSS followed by $120 \mathrm{~d}$ of water ${ }^{[38]}$. Each cycle of DSS consisted of $4 \mathrm{~d}$ of $4 \%$ DSS in the drinking water followed by $17 \mathrm{~d}$ of untreated water. No colorectal lesions were found in untreated $\mathrm{p} 53^{-/-}, \mathrm{p} 53^{+/}$, and $\mathrm{p} 53^{+/+}$mice. The incidence of neoplastic lesions in DSS-treated $\mathrm{p} 53^{-/}, \mathrm{p} 53^{+/-}$, and $\mathrm{p} 53^{+/+}$mice was $57 \%, 20 \%$, and $20 \%$, respectively (Table 2). DSS-treated $\mathrm{p} 53^{-/}$mice had a significantly greater number of total lesions, cancers, and dysplasias per mouse than either DSS-treated $\mathrm{p} 53^{+/-}$or $\mathrm{p} 53^{+/+}$mice. Two important pathological features 
were observed in these animals. First, cancers were found in DSS-treated $\mathrm{p} 53^{+/-}$and $\mathrm{p} 53^{-/-}$mice but not in $\mathrm{p} 53^{+/+}$mice. Second, the predominant morphologic subtype of colorectal neoplasia varied depending on the number of copies of wildtype $\mathrm{p} 53$. The representation of lesion subtypes in DSStreated $\mathrm{p} 53^{-/-}$mice was $38.5 \%$ flat cancers, $46.1 \%$ flat dysplasias, $15.4 \%$ polypoid cancers, and $0 \%$ polypoid dysplasias. In DSS-treated $\mathrm{p} 53^{+/}$mice, the representation of lesion subtypes was $16.7 \%$ flat cancers, $0 \%$ flat dysplasias, $5.6 \%$ polypoid cancers, and $77.8 \%$ polypoid dysplasias. In DSS-treated $\mathrm{p}^{2} 3^{+/+}$mice, all lesions were polypoid dysplasias. These data indicate that flat lesions are associated with the $\mathrm{p} 53^{-/}$genotype, while polypoid lesions are associated with the $\mathrm{p} 53^{+/-}$and $\mathrm{p} 53^{+/+}$genotypes. Irrespective of the $p 53$ genotype, nuclear translocation and mutation of $\beta$-catenin were observed only in polypoid lesions (91\% and $43.7 \%$ respectively). These data indicate that loss of p53 enhances the induction of colitis-associated colorectal neoplasia, in particular flat lesions, and dysregulation of $\beta$-catenin signaling plays an important role in the formation of polypoid lesions in the p53 model of colitis-associated dysplasia.
Fujii et $a l^{[39]}$ have also studied the development of colonic neoplasia in p53-deficient mice with DSS-induced colitis. In this study, $\mathrm{p} 53^{+/+}, \mathrm{p} 53^{+/-}$, and $\mathrm{p} 53^{-/-}$mice were on a C57BL/ $6 \times$ CBA background. Mice were exposed to DSS for 2 cycles ( $7 \mathrm{~d}$ of $4 \%$ DSS plus $14 \mathrm{~d}$ of untreated water per cycle) followed by $84 \mathrm{~d}$ of untreated water (126 d total). Neoplastic lesions were found in $100 \%, 46.2 \%$, and $13.3 \%$ of $\mathrm{p} 53^{-/}, \mathrm{p} 53^{+/-}$, and $\mathrm{p} 53^{+/+}$mice, respectively. The mean number of lesions per mouse was 5.0, 0.62, and 0.2 in p53 $3^{-/-}, \mathrm{p} 53^{+/-}$, and $\mathrm{p} 53^{+/+}$mice, respectively. Invasive adenocarcinomas were seen in $5 \%$ ( 2 of 40 ) of mice. Similar to the study by this group $^{[38]}$, the majority of lesions in $\mathrm{p} 53^{-/-}$mice were flat $(91.7 \%)$, while the majority of lesions in $\mathrm{p} 53^{+/+}$mice were polypoid (66.7\%). Unlike our study, in which nuclear localization was confined to polypoid lesions, Fujii et al ${ }^{[39]}$ observed nuclear staining of $\beta$-catenin in both flat and polypoid neoplasias $(82.6 \%)$.

iNOS An overproduction of reactive oxygen and nitrogen species in chronic ulcerative colitis leads to colonic nitrosative and oxidative stress and depletion of antioxidant molecules. Activation of iNOS causes prolonged produc-

Table 2. DSS-induced Colitis-Associated Colorectal Neoplasms in Genetically Defined Mouse Strains.

\begin{tabular}{|c|c|c|c|c|c|c|c|c|c|}
\hline \multirow[t]{2}{*}{ Gene } & \multirow[t]{2}{*}{ Strain } & \multirow[t]{2}{*}{ Treatment } & \multirow[t]{2}{*}{ Cycles } & \multirow[t]{2}{*}{$\begin{array}{l}\text { Tumor } \\
\text { Incidence } \\
(\%)\end{array}$} & \multirow{2}{*}{$\begin{array}{c}\text { Tumor } \\
\text { Multiplicity } \\
\text { (Mean } \pm \text { SEM) }\end{array}$} & \multicolumn{2}{|c|}{$\begin{array}{c}\text { Incidence of } \\
\text { Neoplastic } \\
\text { Lesions (\%) }\end{array}$} & \multirow[t]{2}{*}{$\begin{array}{l}\text { Invasive } \\
\text { Carcinoma } \\
(\%)\end{array}$} & \multirow[t]{2}{*}{$\begin{array}{r}\text { Refer- } \\
\text { ence }\end{array}$} \\
\hline & & & & & & Polypoid & Flat & & \\
\hline $\mathrm{Apc}^{+/-}$ & $\mathrm{C} 57 \mathrm{BL} / 6 \mathrm{~J}$ & $4 \%$ DSS & $2^{a}$ & 100 & $29.3 \pm 4.1$ & 52 & 37.8 & 40 & 22 \\
\hline $\mathrm{Apc}^{+/-}$ & $\mathrm{C} 57 \mathrm{BL} / 6 \mathrm{~J}$ & $2 \% \mathrm{DSS}$ & $1^{\mathrm{b}}$ & 100 & $13.3 \pm 3.4$ & ND & ND & $100^{\mathrm{c}}$ & 19 \\
\hline $\mathrm{p} 53^{-/-}$ & $\mathrm{C} 57 \mathrm{BL} / 6 \mathrm{~J}$ & $4 \%$ DSS & $3+120$ days & 57 & $1.07 \pm 0.28$ & 15.4 & 84.6 & 53.9 & 38 \\
\hline $\mathrm{p} 53^{+/-}$ & $\mathrm{C} 57 \mathrm{BL} / 6 \mathrm{~J}$ & $4 \% \mathrm{DSS}$ & $3+120$ days & 20 & $0.22 \pm 0.05$ & 83.3 & 16.7 & 22.3 & 38 \\
\hline $\mathrm{p} 53^{+/+}$ & $\mathrm{C} 57 \mathrm{BL} / 6 \mathrm{~J}$ & $4 \%$ DSS & $3+120$ days & 20 & $0.40 \pm 0.32$ & 100 & 0 & 0 & 38 \\
\hline $\mathrm{p} 53^{-/-}$ & $\mathrm{C} 57 \mathrm{BL} / 6 \times \mathrm{CBA}$ & $4 \%$ DSS & $2+84$ days & 100 & $5.0 \pm 0.82$ & 8.3 & 91.7 & $5^{\mathrm{d}}$ & 39 \\
\hline $\mathrm{p} 53^{+/-}$ & $\mathrm{C} 57 \mathrm{BL} / 6 \times \mathrm{CBA}$ & $4 \%$ DSS & $2+84$ days & 46 & $0.6 \pm 0.17$ & 25 & 75 & $5^{\mathrm{d}}$ & 39 \\
\hline $\mathrm{p} 53^{+/+}$ & $\mathrm{C} 57 \mathrm{BL} / 6 \times \mathrm{CBA}$ & $4 \%$ DSS & $2+84$ days & 13.3 & $0.2 \pm 0.14$ & 67 & 33 & $5^{\mathrm{d}}$ & 39 \\
\hline $\mathrm{iNOS}^{-/-}$ & $\mathrm{C} 57 \mathrm{BL} / 6$ & $1 \%$ DSS + high iron diet & $15^{\mathrm{e}}$ & 68.4 & $2.0 \pm 0.2^{f}$ & ND & ND & 100 & 42 \\
\hline iNOS $^{+/+}$ & $\mathrm{C} 57 \mathrm{BL} / 6$ & $1 \%$ DSS + high iron diet & $15^{\mathrm{e}}$ & 65.2 & $1.5 \pm 0.2^{\mathrm{f}}$ & ND & ND & 100 & 42 \\
\hline $\mathrm{Msh} 2^{-/-}$ & 129/OLA x C57BL/6 & $5 \% \mathrm{DSS}$ & $3-8^{g}$ & $60^{\mathrm{h}}$ & ND & ND & ND & 16.7 & 45 \\
\hline $\mathrm{Msh} 2^{+/-}$ & 129/OLA x C57BL/6 & $5 \% \mathrm{DSS}$ & $3-8^{g}$ & $16^{\mathrm{h}}$ & ND & ND & ND & 8.0 & 45 \\
\hline $\mathrm{Msh} 2^{+/+}$ & 129/OLA x C57BL/6 & $5 \% \mathrm{DSS}$ & $3-8^{g}$ & $29.2^{\mathrm{h}}$ & ND & ND & ND & 13.3 & 45 \\
\hline
\end{tabular}

\footnotetext{
${ }^{\text {a }}$ Cycle $1=4$ days of DSS +17 days of untreated water. Cycle $2=3$ days of DSS +18 days of untreated water.

${ }^{\mathrm{b}} 1$ cycle $=7$ days of DSS plus 28 days of water.

${ }^{c}$ Not stated if intramucosal or invasive.

${ }^{\mathrm{d}}$ Represents percentage of invasive cancers for all groups combined.

e 1 cycle $=7$ days of DSS plus 10 days of drinking water.

${ }^{\mathrm{f}}$ Calculated for tumor-bearing mice only.

g 1 cycle $=4-6$ days of DSS plus 14 days of untreated water.

${ }^{\mathrm{h}}$ After 3-5 cycles of DSS (high-grade dysplasia/cancer).

$\mathrm{ND}=$ not determined
} 
tion of NO in cytotoxic concentrations. iNOS has been shown to be overexpressed in the colons of patients with ulcerative colitis and may contribute to the pathogenesis of colitisassociated neoplasia ${ }^{[40,41]}$. Recently, Seril et $a l^{[42]}$ studied the role of iNOS in the development of DSS colitis-associated neoplasia. iNOS ${ }^{-/-}$(C57BL/6 background) and $\mathrm{iNOS}^{+/+}$ (C57BL/6 background) mice were treated with 15 cycles of $1 \%$ DSS ( 1 cycle $=7 \mathrm{~d}$ of DSS plus $10 \mathrm{~d}$ of water) and fed a high-iron AIN76A diet. Mice were sacrificed on day 255. A total of $65.2 \%$ of iNOS $^{+/+}$mice developed tumors as compared to $68.4 \%$ of iNOS $^{-/-}$mice. Tumor multiplicity was $1.5 \pm$ 0.2 and 2.0 \pm 0.2 in $\mathrm{iNOS}^{+/+}$and $\mathrm{iNOS}^{-/-}$mice, respectively. There was no difference in staining intensity for nitrotyrosine between $\mathrm{iNOS}^{-/-}$and $\mathrm{iNOS}^{+/+}$mice. These results suggest that in the absence of iNOS, other factors such as eNos may play a role in nitrosative stress and colitis-associated cancer.

MSH2 Mutation of $\mathrm{MSH} 2$, one of the mismatch repair genes, in humans is associated with the hereditary colorectal cancer syndrome HNPCC (hereditary nonpolyposis colon cancer). The role of loss of function of mismatch repair is unclear in the development of colitis-associated neoplasia in humans ${ }^{[43,44]}$. Colitis was induced in $\mathrm{Msh}^{-/-}, \mathrm{Msh}^{+/-}$, and $\mathrm{Msh}^{+/ /}$mice (on a 129/OLA $\times$C57BL/6 background) using 3-8 cycles of DSS. There was no difference in the severity of colitis between genotypes. After 5 cycles of DSS, 12.5\%, $8.0 \%$, and $46.7 \%$ of $\mathrm{Msh}^{-/-}, \mathrm{Msh}^{+/-}$, and $\mathrm{Msh} 2^{+/+}$mice developed high-grade dysplasia, and $16.7 \%, 8.0 \%$, and $13.3 \%$ of $\mathrm{Msh}^{+/+}, \mathrm{Msh} 2^{+/-}$, and $\mathrm{Msh}^{-/-}$mice developed adenocarcinomas. The majority of adenocarcinomas were of the mucinous type. In Msh2 $2^{-/-}$mice, $77.8 \%$ of tumors were microsatellite instability-high as compared to $0 \%$ in $\mathrm{Msh}^{+/-}$ and $\mathrm{Msh} 2^{+/+}$mice. This model provides an avenue to study the role of DNA mismatch repair in colitis-associated neoplasia in the human ${ }^{[45]}$.

\section{Chemoprevention of DSS-induced colitis- associated neoplasia}

Although the number of chemoprevention studies reported to date in the DSS model is quite limited, emerging data show great promise that colitis-associated colorectal carcinogenesis is indeed a preventable disease. The following section summarizes the ability of select classes of both synthetic and dietary agents to inhibit the formation of DSSinduced neoplasms.

COX-2 inhibitors The significant contribution of COX-2 to the development of sporadic colorectal tumors has been well documented in both preclinical ${ }^{[46]}$ and clinical ${ }^{[47]}$ studies. Based on chronic inflammation as the hallmark of ulcerative colitis, it is anticipated that COX-2 inhibitors will also be highly effective in this disease setting. A small retrospective analysis of celecoxib and rofecoxib use indicates that COX-2 inhibitors are well tolerated by the majority of patients with inflammatory bowel disease ${ }^{[48]}$. Administration of celecoxib (300 ppm in the diet) to Swiss Webster mice with AOM/DSSinduced colitis decreased the multiplicity of colorectal dysplasias by $50 \%{ }^{[23]}$. Interestingly, this inhibitory response appeared to be specific to polypoid ( $v s$ flat) lesions and unrelated to its anti-inflammatory activity. The degree of inflammation in mice receiving AOM, DSS and celecoxib was significantly more severe than that of control mice administered only AOM and DSS.

Nimesulide is a selective COX-2 inhibitor of the sulfonamide class, which is less ulcerogenic than other nonsteroidal anti-inflammatory drugs ${ }^{[49]}$. Long-term feeding of diets supplemented with nimesulide $(0.04 \%, w / w)$ to ICR mice with AOM/DSS-induced colitis caused a significant reduction in the incidence of both adenomas and adenocarcinomas (40\% and $60 \%$, respectively) ${ }^{[50]}$. Drug treatment also decreased total tumor multiplicity 3-fold. Associated reductions in staining for proliferation cell nuclear antigen (PCNA), COX-2, iNOS, $\beta$-catenin and nitrotyrosine, a marker of nitrosative damage, were observed.

PPAR ligands Peroxisome proliferator-activated receptors (PPARs) are nuclear hormone receptors that function as ligand-activated transcription factors. The ability of PPAR ligands to inhibit colorectal adenomas in $\mathrm{Apc}^{+/ \mathrm{Min}}$ mice remains controversial ${ }^{[51-54]}$. Administration of $0.05 \%$ troglitazone $(w / w)$, a ligand of PPAR $\gamma$, to ICR mice with AOM/ DSS-induced colitis significantly inhibited both the incidence and multiplicity of colonic adenocarcinomas by $60 \%$, while bezafibrate, a PPAR $\alpha$ ligand, reduced only tumor incidence significantly ${ }^{[50]}$. These data confirm previous findings by this same group that demonstrate that troglitazone and bezafibrate, as well as another PPAR $\gamma$ ligand, pioglitazone, can suppress the formation of aberrant crypt foci in rats with AOM/DSS-induced colitis ${ }^{[55]}$.

Aminosalicylates Aminosalicylates such as 5-aminosalicylate (5-ASA) have evolved over the past 60 years as the gold standard for the treatment of mild to moderate ulcerative colitis and maintenance of therapeutically induced remissions. However, the ability of this class of agents to prevent colitis-associated neoplasia in patients with ulcerative colitis remains unclear. The effect of 5-ASA on colorectal carcinogenesis has been evaluated in the AOM/DSS mouse model ${ }^{[56,57]}$. An inverse trend between dose of 5-ASA and multiplicity of colorectal dysplasias was observed when Swiss Webster mice with AOM/DSS-induced colitis were adminis- 
tered 5-ASA at 75,150 , or $225 \mathrm{mg} / \mathrm{kg}^{[56]}$. Mice receiving the lowest dose of 5 -ASA ( $75 \mathrm{mg} / \mathrm{kg}$, a clinically relevant dose) exhibited the fewest tumors per animal (7.6 \pm 1.4 and 13.6 \pm 2.7 for drug-treated and AOM/DSS controls, respectively). Grimm et $a l^{[57]}$ studied the chemopreventive effects of low $(100 \mathrm{mg} / \mathrm{kg})$ and high $(300 \mathrm{mg} / \mathrm{kg})$ dose 5 -ASA in the AOM/ DSS model. Mice underwent 2 cycles of DSS treatment after a single ip injection of AOM $(8 \mathrm{mg} / \mathrm{kg})$. High-dose 5 -ASA given for 1 week immediately after the second treatment of DSS significantly reduced the incidence of low- and highgrade dysplasia by $35 \%$ and $100 \%$, respectively, as well as inflammation scores. High-dose 5-ASA given 1 week after the end of the second treatment of DSS blocked the progression of established dysplasia.

Antioxidants Seril et $a l^{[58]}$ have examined the chemopreventive activity of $\mathrm{N}$-acetylcysteine (NAC), an antioxidant and mucolytic agent, in $\mathrm{C} 57 \mathrm{BL} / 6 \mathrm{~J}$ mice treated with $0.7 \%$ DSS for 12 cycles and maintained on an iron-enriched diet. Exposure to $0.2 \%$ NAC significantly reduced tumor incidence from $88.5 \%$ (DSS controls) to $68 \%$ and mean tumor multiplicity from $2.1 \pm 0.2$ (DSS controls) to $1.5 \pm 0.1$. Based on an observed decrease in the number of colonic epithelial cells in NAC-treated mice that stained positive for PCNA, nitrotyrosine and iNOS, the authors conclude that NAC inhibits tumor formation by decreasing both proliferation and the cellular damage induced by nitrosative stress.

Statins Statins are coenzyme A reductase inhibitors that suppress the production of mevalonate, a precursor of cholesterol and geranyl-geranyl diphosphate, and ultimately the prenylation of signal transduction proteins ${ }^{[59]}$. Fluvastatin is a lipophilic statin that readily crosses the cell membrane and decreases the oxidation of low density lipoproteins ${ }^{[60]}$. Administration of fluvastatin to $\mathrm{CBA} / \mathrm{J}$ mice receiving a single injection of AOM and 3 cycles of 3\% DSS dramatically decreased the mean number of high-grade colonic dysplasias per mouse from $27.9 \pm 2.8$ (controls) to $0.8 \pm 0.5$ (drugtreated animals $)^{[61]}$. A drug-induced decrease in the degree of inflammation was confirmed by the detection of fewer cells with positive staining for oxidative damage (8-OHdG). These data provide strong support for further analysis of the efficacy of other statins in the chemoprevention of colitis-associated colorectal neoplasia.

Inositol compounds Polyphosphate inositol compounds are active constituents of high-fiber foods. Inositol hexaphosphate (IP6) is found in whole grains, cereals, legumes, nuts and seeds where it serves as the primary energy source and antioxidant for the germinating plant ${ }^{[62]}$. Phosphoinositides are metabolized to compounds that regulate enzyme activities and protein phosphorylation in the cell membrane, nucleus and cytoplasm. The antitumor activity of IP6 has been documented in several models of chemically induced carcinogenesis (see Fox et al for review) ${ }^{[63]}$. The efficacy of IP6 and inositol against inflammation-associated carcinogenesis has been examined in C57BL/6J mice given DSS for 15 cycles and fed a diet enriched in iron for the duration of the study ${ }^{[64]}$. The addition of $1 \%$ inositol to the drinking fluid of DSS-treated mice reduced tumor incidence, multiplicity and volume significantly to $61 \%, 40 \%$, and $20 \%$ of that of DSStreated controls, respectively. In contrast, administration of 1\% IP6 in the drinking fluid had no significant effect on the formation of colitis-associated neoplasias. Results from associated mechanistic studies suggest that inositol may inhibit colitis-associated colorectal carcinogenesis by reducing macrophage-mediated inflammation, nitrooxidative stress and cell proliferation.

Prenyloxycoumarins Prenyloxycoumarins are secondary metabolites found in plants of the Rutaceae (ie, orange, lemon, lime, grapefruit) and Umbelliferae (ie, carrots, parsley, caraway, fennel) families that possess anti-inflammatory properties. Tanaka et al ${ }^{[65]}$ reported that Citrus auraptene inhibits chemically induced aberrant crypt foci in rats. Extension of this observation to inflammatory bowel disease yielded a similar result. Exposure of ICR mice with AOM/ DSS-induced colitis to diets supplemented with either auraptene or collinin for 17 weeks significantly reduced both tumor incidence and the number of lesions per animal at both doses tested $(0.01 \text { and } 0.05 \%)^{[66]}$. Enhanced apoptosis and decreased proliferation, iNOS and COX-2 were noted.

In summary, preclinical studies conducted to date support the use of the mouse model of DSS-induced colitis as a highly relevant system in which to further characterize the molecular events required for the formation of colorectal neoplasia in a background of chronic inflammation. Results from chemopreventive intervention studies provide evidence that colitis-associated colorectal cancer can be prevented. Future experimentation in this model is anticipated to facilitate the development of an efficacious chemopreventive regimen for patients with ulcerative colitis.

\section{Acknowledgments}

We thank Dr Tony KONG for providing us with an opportunity to review this exciting area of research, and Maureen CLIMALDI for her excellent assistance in preparing this manuscript for publication.

\section{References}

1 Eaden JA, Abrams KR, Mayberry JF. The risk of colorectal can- 
cer in ulcerative colitis: a meta-analysis. Gut 2001; 48: 526-35.

2 Hardy RG, Meltzer SJ, Jankowski JA. ABC of colorectal cancer. Molecular basis for risk factors. BMJ 2000; 321: 886-9.

3 Harpaz N, Talbot IC. Colorectal cancer in idiopathic inflammatory bowel disease. Sem Diagn Pathol 1996; 13: 339-57.

4 Ekbom A, Helmick C, Zack M, Adami HO. Ulcerative colitis and colorectal cancer. A population-based study. N Engl J Med 1990; 323: $1228-33$.

5 Rutter MD, Saunders BP, Wilkinson KH, Rumbles S, Schofield G, Kamm MA, et al. Thirty-year analysis of a colonoscopic surveillance program for neoplasia in ulcerative colitis. Gastroenterology 2006; 130: 1030-8.

6 Farrell RJ, Peppercorn MA. Ulcerative colitis. Lancet 2002; 359: 331-40.

7 Kiesslich R, Fritsch J, Holtmann M, Koehler HH, Stolte M, Kanzler S, et al. Methylene blue-aided chromoendoscopy for the detection of intraepithelial neoplasia and colon cancer in ulcerative colitis. Gastroenterology 2003; 124: 880-8.

8 Kern SE, Redston M, Seymour AB, Caldas C, Powell SM, Kornacki $\mathrm{S}$, et al. Molecular genetic profiles of colitis-associated neoplasms. Gastroenterology 1994; 107: 420-8.

9 Aust DE, Terdiman JP, Willenbucher RF, Chang CG, MolinaroClark A, Baretton GB, et al. The APC/ $\beta$-catenin pathway in ulcerative colitis-related colorectal carcinomas. A mutational analysis. Cancer 2002; 94: 1421-7.

10 Hussain SP, Amstad P, Raja K, Ambs S, Nagashima M, Bennett WP, et al. Increased p53 mutation load in noncancerous colon tissue from ulcerative colitis: a cancer-prone chronic inflammatory disease. Cancer Res 2000; 60: 3333-7.

11 Brentnall TA, Crispin DA, Bronner MP, Cherian SP, Hueffed M, Rabinovitch PS, et al. Microsatellite instability in nonneoplastic mucosa from patients with chronic ulcerative colitis. Cancer Res 1996; 56: 1237-40.

12 Chang CL, Marra G, Chauhan DP, Ha HT, Chang DK, Ricciardiello $\mathrm{L}$, et al. Oxidative stress inactivates the human DNA mismatch repair system. Am J Physiol Cell Physiol 2002; 283: C148-54.

13 Fogt F, Vortmeyer AO, Goldman H, Giordano TJ, Merino MJ, Zhuang Z. Comparison of genetic alterations in colonic adenoma and ulcerative colitis-associated dysplasia and carcinoma. Hum Pathol 1998; 29: 131-6.

14 Yashiro M, Carethers JM, Laghi L, Saito K, Slezak P, Jaramillo $\mathrm{E}$, et al. Genetic pathways in the evolution of morphologically distinct colorectal neoplasms. Cancer Res 2001; 61: 2676-83.

15 Wong NACS, Harrison DJ. Colorectal neoplasia in ulcerative colitis-recent advances. Histopathology 2001; 39: 221-34.

16 Ohkusa T. Production of experimental ulcerative colitis in hamsters by dextran sulfate sodium and change in intestinal microflora. Jpn J Gastroenterol 1985; 82: 1327-36.

17 Okayasu I, Hatekayama S, Yamada M, Ohkusa T, Inagaki Y, Nakaya R. A novel method in the induction of reliable experimental acute and chronic ulcerative colitis in mice. Gastroenterology 1990; 98: 694-702.

18 Cooper HS, Murthy SNS, Shah RS, Sedergran DJ. Clinicopathologic study of dextran sulfate sodium experimental murine colitis. Lab Invest 1993; 69: 238-49.

19 Tanaka T, Kohno H, Suzuki R, Hata K, Sugie S, Niho N, et al. Dextran sodium sulfate strongly promotes colorectal carcinogenesis in $A p c^{M i n /+}$ mice: inflammatory stimuli by dextran sodium sulfate results in development of multiple colonic neoplasms. Int
J Cancer 2006; 118: 25-34.

20 Cooper HS, Murthy S, Kido K, Yoshitake H, Flanigan A. Dysplasia and cancer in the dextran sulfate sodium mouse colitis model. Relevance to colitis-associated neoplasia in the human: a study of histopathology, B-catenin and p53 expression and the role of inflammation. Carcinogenesis 2000; 21: 757-68.

21 Nosho K, Yamamoto H, Adachi Y, Endo T, Hinoda Y, Imai K. Gene expression profiling of colorectal adenomas and early invasive carcinomas by cDNA array analysis. Br J Cancer 2005; 92: 1193-200.

22 Cooper HS, Everley L, Chang W-C, Pfeiffer G, Lee B, Murthy S, et al. The role of mutant Apc in the development of dysplasia and cancer in the mouse model of dextran sulfate sodium-induced colitis. Gastroenterology 2001; 121: 1407-16.

23 Coudry RA, Cooper HS, Gary M, Lubet RA, Chang WCL, Clapper ML. Correlation of inhibition of colitis-associated dysplasia by celecoxib with degree of inflammation in the mouse model of DSS-induced colitis. Proc Am Assoc Cancer Res 2004; 45: 548.

24 Tanaka T, Kohno H, Suzuki R, Yamada Y, Sugie S, Mori H. A novel inflammation-related mouse colon carcinogenesis model induced by azoxymethane and dextran sodium sulfate. Cancer Sci 2003; 94: 965-73.

25 Suzuki R, Kohno H, Sugie S, Nakagama H, Tanaka T. Strain differences in the susceptibility to azoxymethane and dextran sodium sulfate-induced colon carcinogenesis in mice. Carcinogenesis 2006; 27: 162-9.

26 Takahashi M, Nakatsugi S, Sugimura T, Wakabayashi K. Frequent mutations of the $\beta$-catenin gene in mouse colon tumors induced by azoxymethane. Carcinogenesis 2000; 21: 1117-20.

27 Tanaka T, Suzuki R, Kohno H, Sugie S, Takahashi M, Wakabayashi $\mathrm{K}$. Colonic adenocarcinomas rapidly induced by the combined treatment with 2-amino-1-methyl-6-phenylimidazo[4,5-b]pyridine and dextran sodium sulfate in male ICR mice possess $\beta$-catenin gene mutations and increases immunoreactivity for $\beta$ catenin, cyclooxygenase- 2 and inducible nitric oxide synthase. Carcinogenesis 2005; 26: 229-38.

28 Aust DE, Terdiman JP, Willenbucher RF, Chew K, Ferrell L, Florendo $\mathrm{C}$, et al. Altered distribution of $\beta$-catenin, and its binding proteins E-cadherin and APC, in ulcerative colitis-related colorectal cancers. Mod Pathol 2001; 14: 29-39.

29 Souza RF, Yin J, Smolinski KN, Zou TT, Wang S, Shi YQ, et al. Frequent mutation of the E2F-4 cell cycle gene in primary human gastrointestinal tumors. Cancer Res 1997; 57: 2350-3.

30 Sugimura T. Nutrition and dietary carcinogens. Carcinogenesis 2000; 21: 387-95.

31 Nagao M. A new approach to risk estimation of food-borne carcinogens-heterocyclic amines-based on molecular information. Mutat Res 1999; 431: 3-12.

32 Sugimura T. Overview of carcinogenic heterocyclic amines. Mutat Res 1997; 376: 211-9.

33 Nishikawa A, Imazawa T, Kuroiwa Y, Kitamura Y, Kanki K, Ishii $\mathrm{Y}$, et al. Induction of colon tumors in C57BL/6J mice fed MeIQx, IQ, or PhIP followed by dextran sulfate sodium treatment. Toxicol Sci 2005; 84: 243-8.

34 Carrier J, Aghdassi E, Cullen J, Allard JP. Iron supplementation increases disease activity and vitamin $E$ ameliorates the effect in rats with dextran sulfate sodium-induced colitis. J Nutr 2002; 132: 3146-50.

35 Seril DN, Liao J, Ho KL, Warsi A, Yang CS, Yang GY. Dietary 
iron supplementation enhances DSS-induced colitis and associated colorectal carcinoma development in mice. Dig Dis Sci 2002; 47: $1266-78$.

36 Cooper HS, Chang WCL, Coudry R, Gary MA, Everley L, Spittle $\mathrm{CS}$, et al. Generation of a unique strain of multiple intestinal neoplasia $\left(\mathrm{Apc}^{+/ \mathrm{Min}-\mathrm{FCCC}}\right)$ mice with significantly increased numbers of colorectal adenomas. Mol Carcinog 2005; 44: 31-41.

37 Burmer GC, Crispin DA, Kolli VR, Haggitt RC, Kulander BG, Rubin CE, et al. Frequent loss of a p53 allele in carcinomas and their precursors in ulcerative colitis. Cancer Commun 1991; 3: $167-72$.

38 Chang WC, Coudry RA, Clapper ML, Zhang X, Williams KL, Spittle CS, et al. Loss of p53 enhances the induction of colitisassociated neoplasia by dextran sulfate sodium. Carcinogenesis 2007 June 8; [Epub ahead of print].

39 Fujii S, Fujimori T, Kawamata H, Takeda J, Kitajima K, Omotehara $\mathrm{F}$, et al. Development of colonic neoplasia in p53 deficient mice with experimental colitis induced by dextran sulphate sodium. Gut 2004; 53: 710-6.

40 Wink DA, Vodovotz Y, Laval J, Laval F, Dewhirst MW, Mitchell JB. The multifaceted roles of nitric oxide in cancer. Carcinogenesis 1998; 19: 711-21.

41 Jaiswal M, LaRusso NF, Gores GJ. Nitric oxide in gastrointestinal epithelial cell carcinogenesis: linking inflammation to oncogenesis. Am J Physiol 2001; 281: G626-G34.

42 Seril DN, Liao J, Yang GY. Colorectal carcinoma development in inducible nitric oxide synthase-deficient mice with dextran sulfate sodium-induced ulcerative colitis. Mol Carcinog 2007; 46: 341-53.

43 Fleisher AS, Esteller M, Harpaz N, Leytin A, Rashid A, Xu Y, et al. Microsatellite instability in inflammatory bowel disease-associated neoplastic lesions is associated with hypermethylation and diminished expression of the DNA mismatch repair gene, hMLH1. Cancer Res 2000; 60: 4864-8.

44 Cawkwell L, Sutherland F, Murgatroyd H, Jarvis P, Gray S, Cross $\mathrm{D}$, et al. Defective hMSH2/hMLH1 protein expression is seen infrequently in ulcerative colitis associated colorectal cancers. Gut 2000; 46: 367-9.

45 Kohonen-Corish MR, Daniel JJ, te Riele H, Buffinton GD, Dahlstrom JE. Susceptibility of Msh2-deficient mice to inflammation-associated colorectal tumors. Cancer Res 2002; 62: 2092-7.

46 Oshima M, Dinchuk JE, Kargman SL, Oshima H, Hancock B, Kwong E, et al. Suppression of intestinal polyposis in $A p c^{\Delta 716}$ knockout mice by inhibition of cyclooxygenase 2 (COX-2). Cell 1996; 87: 803-9.

47 Steinbach G, Lynch P, Phillips RKS, Wallace MH, Hawk E, Gordon GB, et al. The effect of celecoxib, a cyclooxygenase-2 inhibitor, in familial adenomatous polyposis. N Engl J Med 2000; 342: 1946-52.

48 Mahadevan U, Loftus EV, Tremaine WJ, Sandborn WJ. Safety of selective cyclooxygenase-2 inhibitors in inflammatory bowel disease. Am J Gastroenterol 2002; 97: 910-4.

49 Kapicioglu S, Baki AH, Sari M, Ozdemir F, Kavgaci H. Does nimesulide induce gastric mucosal damage? "A double-blind randomized placebo-controlled trial". Hepatogastroenterology 2000; 47: $1183-5$.

50 Kohno H, Suzuki R, Sugie S, Tanaka T. Suppression of colitisrelated mouse colon carcinogenesis by a COX-2 inhibitor and
PPAR ligands. BMC Cancer 2005; 5: 46.

51 Niho N, Takahashi M, Kitamura T, Shoji Y, Itoh M, Noda T, et al. Concomitant suppression of hyperlipidemia and intestinal polyp formation in Apc-deficient mice by peroxisome proliferator-activated receptor ligands. Cancer Res 2003; 63: 6090-5.

52 Girnun GD, Smith WM, Drori S, Sarraf P, Mueller E, Eng C, et al. APC-dependent suppression of colon carcinogenesis by PPAR $\gamma$. Proc Natl Acad Sci USA 2002; 99: 13771-6.

53 Lefebvre AM, Chen I, Desreumaux P, Najib J, Fruchart JC, Geboes $\mathrm{K}$, et al. Activation of the peroxisome proliferator-activated receptor $\gamma$ promotes the development of colon tumors in $\mathrm{C} 57 \mathrm{BL} /$ 6J-APC ${ }^{\mathrm{Min} /+}$ mice. Nat Med 1998; 4: 1053-7.

54 Saez E, Tontonoz P, Nelson MC, Alvarez JG, Ming UT, Baird $\mathrm{SM}$, et al. Activators of the nuclear receptor PPAR $\gamma$ enhance colon polyp formation. Nat Med 1998; 4: 1058-61.

55 Tanaka T, Kohno H, Yoshitani S, Takashima S, Okumura A, Murakami A, et al. Ligands for peroxisome proliferator-activated receptors $\alpha$ and $\gamma$ inhibit chemically induced colitis and formation of aberrant crypt foci in rats. Cancer Res 2001; 61: 2424-8.

56 Gary MA, Coudry RA, Cooper HS, Litwin S, Concha AC, Lubet RA, et al. 5-Aminosalicylic acid inhibits colitis-associated dysplasia in the mouse model of AOM/DSS-induced colitis. Proc Am Assoc Cancer Res Third Annual International Conference on Frontiers in Cancer Prevention Research 2004; 45: A81.

57 Grimm GR, Dirisina R, Lee G, Tang Y, Manjali J, Hanson NB, et al. 5-ASA suppressed induction of dysplasia on the AOM/DSS model: Correlation with inhibition of Wnt/beta-catenin transcriptional activity. Gastroenterology 2005; 128 (Suppl 2): A200.

58 Seril DN, Liao J, Ho KL, Yang CS, Yang GY. Inhibition of chronic ulcerative colitis-associated colorectal adenocarcinoma development in a murine model by $\mathrm{N}$-acetylcysteine. Carcinogenesis 2002; 23: 993-1001.

59 Morris AJ, Malbon CC. Physiological regulation of G proteinlinked signaling. Physiol Rev 1999; 79: 1373-430.

60 Goldstein JL, Brown MS. Regulation of low-density lipoprotein receptors: implications for pathogenesis and therapy of hypercholesterolemia and atherosclerosis. Circulation 1987; 76: 504-7.

61 Suzuki S, Tajima T, Sassa S, Kudo H, Okayasu I, Sakamoto S. Preventive effect of fluvastatin on ulcerative colitis-associated carcino-genesis in mice. Anticancer Res 2006; 26: 4223-8.

62 Raboy V. Myo-Inositol-1,2,3,4,5,6-hexakisphosphate. Phytochemistry 2003; 64: 1033-43.

63 Fox CH, Eberl M. Phytic acid (IP6), novel broad spectrum antineoplastic agent: a systematic review. Complement Ther Med 2002; 10: 229-34.

64 Liao J, Seril DN, Yang AL, Lu GG, Yang GY. Inhibition of chronic ulcerative colitis associated adenocarcinoma development in mice by inositol compounds. Carcinogenesis 2007; 28: 446-54.

65 Tanaka T, Kawabata K, Kakumoto M, Makita H, Hara A, Mori $\mathrm{H}$, et al. Citrus auraptene inhibits chemically induced colonic aberrant crypt foci in male F344 rats. Carcinogenesis 1997; 18 : 2155-61.

66 Kohno H, Suzuki R, Curini M, Epifano F, Maltese F, Gonzales $\mathrm{SP}$, et al. Dietary administration with prenyloxycoumarins, auraptene and collinin, inhibits colitis-related colon carcinogenesis in mice. Int J Cancer 2006; 118: 2936-42. 